\title{
Empirical Musicology Review: Serialist Claims versus Sonic Reality
}

\author{
WILLIAM THOMSON \\ University of Southern California
}

\begin{abstract}
This study examines the descriptive mores of Serialism, as found in writings of leading American academics of the past half-century. A serious gap is revealed, especially between claims made for structural conditions rooted in dodecaphonic procedures and the actual kinetics of music as heard. Curious (and debilitating) ambiguities and dead ends are noted in terms used to define critical perceptual conditions in such music; some claims of significance for features of 12tone rows in certain works are revealed as wholly irrelevant to music as sonic event. Most prominent of the writings discussed are those of Milton Babbitt, Allen Forte and David Lewin. ${ }^{[1]}$
\end{abstract}

Submitted 2010 January 1; accepted 2010 April 7.

KEYWORDS: Serialism, 12-tone method, music perception

IT is no exaggeration to claim that Serialism was the dominating conceptualization of Art music during the $20^{\text {th }}$-century. Initiated by Arnold Schoenberg and Josef Hauer as the "12-tone method," its basic motivations and technical controls became the most sensational — and for many the most credible — answer to questions of "where music's future was headed." With some irony, few composers of today employ its operational canons, yet it lingers on as a major subject in graduate studies of colleges and universities (Thomson, 1993-1994).

For those lacking direct familiarity with the "method", its basis is not daunting, although its ramifications can be. Simply put, it is a way for structuring the pitch content of a composition, usually using the twelve notes (or pitch-classes ${ }^{[2]}$ ) of the chromatic scale as its raw source. A structured "row" (or "series") can then be incorporated in its wealth of permutations, including Inversion $(I)$, Retrograde $(R)$, and Retrograde Inversion (RI).

Empirical investigations of the method's theoretical base and its claims to artistic and perceptual relevance find it wanting. ${ }^{[3]}$ Studies of music perception, as well as the dormant state of the approach as compositional tool, are major sources of information. Studies from over the past several decades suggest that essential elements of the approach to composing lack confirmation as perceptually meaningful. But music historians and theoreticians have comfortably moved on to related topics of more current import, preferring to ignore what is past, refraining from hard-nosed attention to what riveted our attention as Music's avant for over seven decades.

Serialism's major proponents are among the most respected of modern music scholars. Among them, Princeton's Milton Babbitt was unquestionably the most imposing. His role in the groundbreaking Princeton-Columbia Computer Center in NYC of the 1960s further solidified his prominence as a NewAge music guru. A principal figure in the periodical Perspectives of New Music expressed what slowly emerged as a basic truth for a limited segment of the academic world: Babbitt played a leading role in developing post-war musical thought and explanation. His significance "for musical composition, theory, and pedagogy in the United States is beyond that of any other individual." ${ }^{[4]}$ His "scientific" approach to musical matters led to his appointment as a Fellow of the American Academy of Arts and Sciences, as well as the American Academy of Arts and Letters.

Yale's Allen Forte provided systemic support, adding conceptual and organizational insights that furthered the movement's scientific tone. Then, Harvard's David Lewin began catching up in the Ivy League triumvirate by the late 1960s. Their theorizing developed a fascinating condition: here was a daunting "science" of a sort, but one whose real-world basis - in what it purported to describe as sonic events-left many vital questions unanswered. It's easy to recognize the armchair delights available from a collection of permutable elements, whether they are numbers, playing cards, words, people, or notes. Just the nine elements of a Sudoku puzzle can tantalize for hours. And in 12-tone theorizing there were twelve for the playing. 
Beyond the American Ivy-league triumvirate of Babbitt, Forte, and Lewin, there were Pierre Boulez, George Perle, and George Rochberg. Of the total, Boulez, Babbitt, Perle, and Rochberg were also prominent among those who utilized such techniques in composing, although Rochberg dramatically defected in the $1960 \mathrm{~s} .{ }^{[5]}$ Whatever may or may not have been imagined as their musical import, the ideological trappings of Serialism forged a major schism in how some people thought about musical things. The doctrine's efflorescence and frequent turns to mathematics in its descriptives can easily subdue the innocent, so it is important that the unblessed have some inkling of their potential irrelevance. Let us glance into the gist and substances of just a select number of such positings, enough to recognize their depth, their breadth, their esotericism, and their ragged relevance to the actual kinetics of music as heard.

For a point of departure, Milton Babbitt's prose is unmatched. Seminal for those who followed his path, it is arguably the most provocative — in style as well as in substance — of any serialist tracts from the mid-century. He contended early in the game that an acceptable theory of music must supply a basis for understanding "unprecedented musical utterances." Such a theory, he added, must also provide a "model for determinate and testable statements about musical compositions" (Babbitt, 2003, p. 171). They are worthy goals. Both are central to our concerns here. Indeed, our task will be to test some of his decipherings against his own stated demands.

An early (and typical) contribution of the Babbitt oeuvre is a detailed description of pitch components he finds primal to the third movement of Schoenberg's Fourth String Quartet (see Figure 1). Forgive the quotation's length: that is a secondary part of my overarching point. (I have deleted the paragraph's first 39 words.)

Even a cursory examination reveals a number of significant techniques of local continuity and association: the exploitation of ordered adjacencies (the repeated adjacencies C-B of bar 619 and G-flat-F of bar 617 cross-associate with the opening two notes of the movement and the G-flat - F of the first violin in bar 621 to effect the closure of a structural unit: the three-note adjacency C-B$\mathrm{G}$ of 619 also registrationally duplicates the first three notes of the movement); the delinearization (the dyads of the first violin line of 620-21 are distributed among the three instruments that immediately follow); intervallic preparation and association (the simultaneously stated fourths of 619,620 , and 621 prepare the predefined fourth of the cello and viola in 623; the repeated C -B states with regard to the $\mathrm{G}$ in 619 the intervallic succession continued by the relation of the Dsharp- $\mathrm{E}$ to the $\mathrm{B}$ in the same measure); motivic progression (the joining of forms of the set in 618 gives rise to the motive stated in the prime set itself by the last three notes, and the third, fourth, and fifth notes; $;{ }^{[6]}$ the distribution of the elements of the inverted set between second violin and viola in 623 results in a three-note motive in the second violin which is the retrograde inversion of notes five, six and seven of the simultaneously stated prime, at precisely the same total pitch level, and at the same time, the resultant viola line reveals two sixteenth-note groups of four notes each which symmetrically permute the minor second and major third); functional "orchestration" (the six-note unit of the first violin in 620-21 combines with the six-note unit of 622-23 to form a set); et cetera (Babbitt, 2003, p. 41). 

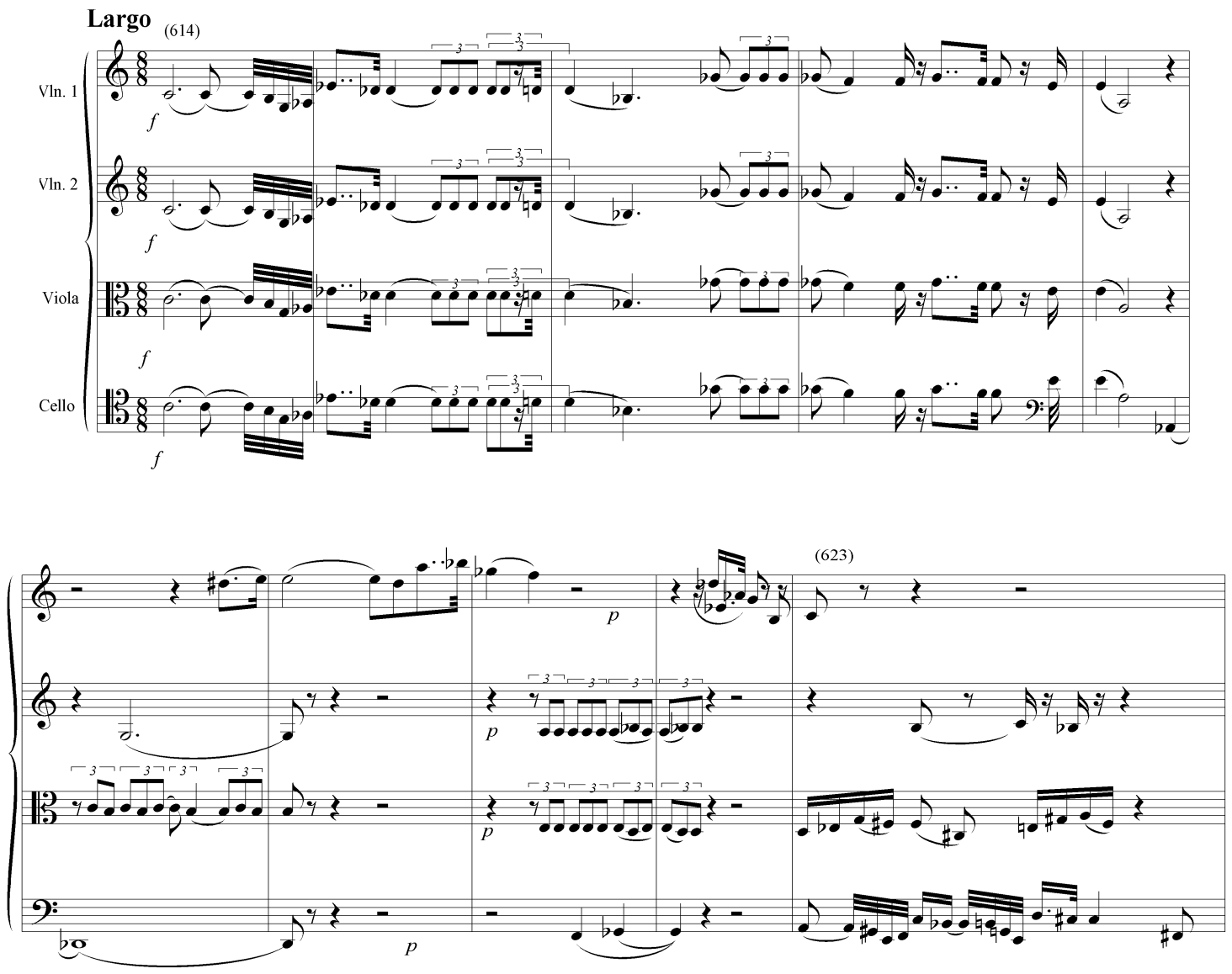

Figure 1. Schoenberg, Fourth String Quartet, mm. 614-623, reprinted by permission of Belmont Music Publishers.

Even those who follow musical notation find this Faulknerian sentence of 285 words tough sledding. It reflects the substance and style of much serialist shoptalk, a fit for Roger Kimball's coinage "aggressive impenetrability."

Of immediate interest for us are the implied meanings of several key words. Our concern is for the experiential assumptions they imply-words like local continuity, closure, preparation, association, and progression. It is hard to accept the real-world sonic implications they bear as Babbitt states them. Let us first rummage through each of his claims to consider their perceptual relevance. It will be tedious, but a less thorough appraisal could not achieve our goals. I have italicized words whose implications are critical.

First:

"Even a cursory examination reveals a number of significant techniques of local continuity and association: [1a] the exploitation of ordered adjacencies (the repeated adjacencies C-B of bar 619 and G-flat-F of bar 617 cross-associate with the opening two notes of the movement and [1b] the G-flat - F of the first violin in bar 621 to effect the closure of a structural unit:"

Observe that the quartet's row contains a large number of semitones (five). ${ }^{[7]}$ For this reason alone, one might expect that interval and its displacements to play a prominent role in patterns assembled from the row. Recognizing that majority leads us to wonder: Could the occurrence of a single interval, without reinforcing rhythmic, textural, dynamic, or contoural features, project a sense of "association" with a corresponding segment of a row, binding with that earlier segment to project a structural base?

Semitones do play a notable role in this $3^{\text {rd }}$ movement. There are nonetheless good reasons for skepticism about the correspondences Babbitt finds crucial. Note first that [1a] the semitone $C-B$ he isolates from measure 1 is too fleeting to achieve motivic stature, to be remembered for later claims of 
"cross-association" with such as the $G$-flat $-F$ found three measures later (m. 617). ${ }^{[8]}$ The opening statement's principal pitches - its defining pitches as heard-are $C-E$-flat $-D$-flat $-D$-natural $-B$-flat, the latter two forming a rhythmic closure. Potential semitonal flags are raised by the $C-D$-flat $-D$-natural presence; but a careful examination reveals that interval's appearance most often in rhythmically secondary roles. In measures $619-624$, for instance, semitones occur only as auxiliaries to rhythmically more prominent pitches.

There is no evidence in these measures of contexts primed by "ordered adjacencies." As previously mentioned, five semitones ${ }^{[9]}$ in the row implies their probability of turning up often within the music. But lacking special circumstances, they are pitted against too many competing intervals of greater contextual prominence to achieve structural status. Furthermore, any claim [1b] of closure projected by the $G$-flat $-F$ in m. 621 suggests something that music's history has never disclosed: the "closure" power of a descending semitone. It's an especially risky forecast within a context lacking any projection of tonal hierarchy. ${ }^{[10]}$

And then a second claim:

"the three-note adjacency $C-B-G$ of 619 also registrationally duplicates the first three notes of the movement);"

Again, let us recall that Babbitt's $C-B-G$ touchstone wasn't stated in the opening measure in a way that ascends to auditory prominence. Pitches $B-G-A$-flat in that location are but fleeting wisps between $C$ and $E$-flat. Perhaps the same interval succession from the Quartet's first movement (in the form of $D-C$-sharp-A) might be recalled by a listener. But even in that movement it isn't repeated in ways that hark of motivic status. Further, the chordal $C-B-G$ of Vln. II and viola in m. 619 are hard to associate with the opening's linear statement, especially in view of the dissonant environment they form with the cello's D-flat. That they are registral duplicates seems thematically beside the point.

\section{And to POINT 3:}

"delinearization (the dyads of the first violin line of 620-21 are distributed among the three instruments that immediately follow);"

This claimed "preparation" and "association" risks an especially broad leap from written notes to heard music. Indeed, the chordal $A-E-B$-flat $-D$ of Vln. II and Vla., plus the cello's $F-G$-flat, do exhaust Vln I's $E-D-A-B$-flat $-G$-flat $-F$ line. But concluding that even the most alert listener might distill these correspondences into an association (3-voice texture with earlier line) assumes an unlikely coalescing of bits and pieces. And last, the cello's retrograded $F-G$-flat offers an improbable association with the preceding $G$-flat $-F$ of Vln. I-except as corresponding note names. It is one of those detectable affinities in notes unlikely to arouse memorable kinships in the ear.

\section{POINT 4:}

"intervallic preparation and association (the simultaneously stated fourths of 619, 620, and 621 prepare the predefined fourth of the cello and viola in $623 ; "$

Let us recall that the $G-C 4^{\text {th }}$ formed by Vln. II and Vla. in m. 619 is not sonically imposing, especially in its surrounding dissonant context. Assigning it a "preparation" and "association" role for the equally unimposing (and fleeting) $A-D 4^{\text {th }}$ of 623 is whimsical at best. Even prominence as a defining pitch of the viola's $D$ is questionable, since it functions only as a neighbor tone for the $E$-flat. Thus far we have been led to believe that the semitone, the M3rd and the P4th have been stamped with a sense of importance. That the interval of a $4^{\text {th }}$ also has been "predefined" in some notable way, making it a kind of intervallic touchstone, is another broad leap of faith. Added to the already exposed M3 and semitone as intervals of prominence, it overloads the dice.

\section{POINT 5:}

"the repeated $C-B$ states with regard to the $G$ in 619 the intervallic succession continued by the relation of the $D$-sharp- $E$ to the $B$ in the same measure;"

Pitch $B$ occurs only in the viola part, so we must wonder where these designated trichord relations reside to justify the tie of Vln. I's $D \#-E$ to the lower texture. Since the $B$ is only in the Vla., any linkage between the Viola and Vln. I fragment is risky. ${ }^{[1]}$ What Babbitt must have in mind are the inversionally related 3-note segments, yet they are not really inversionally related. ${ }^{[12]}$ 


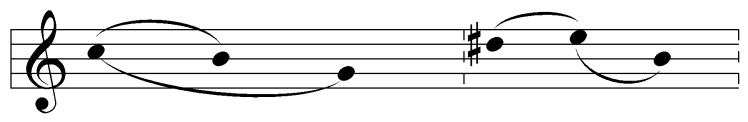

Figure 2. Trichords from Vln. I and Viola, m. 619.

And note that Vln. I's entrance, with its imposing rhythm, contour, and registral contrast, further blocks out any continuing sense of the $B$ 's presence in the viola; it also reduces the chance that the Vln. II/Vla./Cello presence might be heard as more than accompanimental (and thus secondary).

\section{POINT 6:}

"motivic progression (the joining of forms of the set in 618 gives rise to the motive stated in the prime set itself by the last three notes, and the third, fourth, and fifth notes);"

Babbitt's claim here involves the inversional relation of the row's 3-4-5 (G-A-flat $-E-f l a t)$ and 10-11-12 $(F-E-A)$ notes and establishment of their motivic prominence. The only interval of that "motivic" $4^{\text {th }}$ occurs between the Viola and the Violin $E$ in m. 620. In that setting it is less than impressive, even though the Viola's $B$ was prominent in the preceding measure. So how this alleged "joining of forms" into a motivic presence is projected in Schoenberg's music — even in notes - remains a mystery. Perhaps we must coin a riff on Tom Wolfe. Now it is "Believing is hearing!"

POINT: 7:

"[a] the distribution of the elements of the inverted set between second violin and viola in 623 results in a three-note motive in the second violin which is the retrograde inversion of notes five, six and seven of the simultaneously stated prime, at precisely the same total pitch level, and at the same time, [b] the resultant viola line reveals two sixteenth-note groups of four notes each which symmetrically permute the minor second and major third);"

Let us first observe that [a] the references are to Vln. II's $B-C-B$-flat, which is the retrograde inversion of the Cello's $C-B$-flat $-B$. In other words,

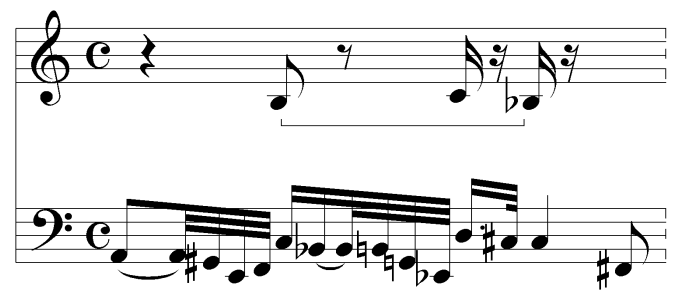

Figure 3. Cello and Vln. I, m.623.

And [b], the viola line permutations of the $C-B-G$ pattern (alleged to have been established in $\mathrm{m} .1$ ) occur here in the form of

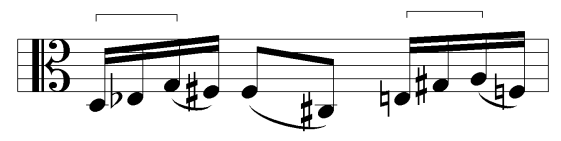

Figure 4. Viola, m. 623.

And finally, POINT 8:

"functional "orchestration" (the six-note unit of the first violin in 620-21 combines with the sixnote unit of 622-23 to form a set); et cetera."

This tells us that Vln. I's six notes of mm. 622-23 complete the row with the six sounded in 620-21:23 


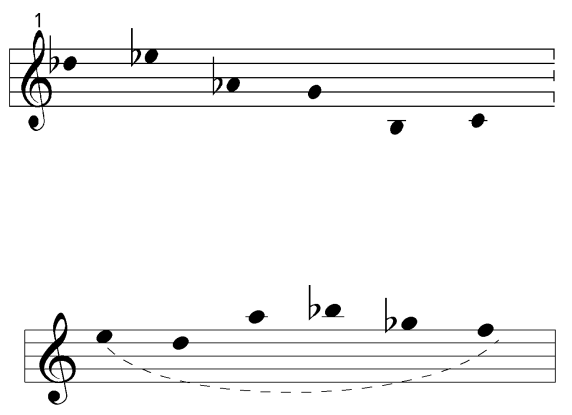

Figures 5 and 6: Derived row, Vlns. I and II, Viola, m. 620-621.

And this is no doubt true as well as interesting. But, once again, this note-fact bears weak relevance to sonic reality. I have no sense of pattern-fulfillment, of a row-completion, when I hear mm. 622-23. Empirical studies have shown repeatedly that a listener is unlikely to encapsulate any six-note succession for matching to a subsequent permutation - unless those pitches are embedded in highly memorable contexts (Bruner, 1984; Deutsch, 1980; Dibben, 1994; Dienes \& Longuet-Higgins, 2004; Krumhansl, Sandell \& Sargeant, 1987). These 6 x 6 partitionings are fleeting bits; their "meanings" as segments of a 12-note union are unlikely to be apprehended as such. There is no context within which contributing parts can be linked.

Such fastidiously sought and precisely claimed row/note implants give us some perspective on how Schoenberg put together the pitches of his Quartet. On that score Professor Babbitt's analysis is insightful. But there remains that central imposing problem hidden within. It arises from the fact that such enumerations suggest matters of perceptual import, sonic cement that holds the music together for a listener. They fail in that regard. They fail by disregarding the actual kinetics, the pitches-in-time universe in which the musical experience is grounded, the interactions that project musical meaning. Babbitt's error is not a rare one. Its nature and source are common baggage carried by some contemporary musicians. When we analyze music from its notated page we tend to emphasize only those things represented by notes. They are objective evidence. We can trust them. But music notation cannot fully reflect the whole, the dynamics of sonic reality.

An implicit conviction underlies these careful exhumations of note constructs, a conviction basic to serialist doctrine. It holds that individual pitch-classes and groupings of pitch-classes assume central roles in the musical process. It is a flawed belief (Thomson, 1991). The implication that recurring semitones and replicated hexachords, like those detailed by Babbitt, provide a perceptual glue is no more confirmed in the listening process than it is by recent empirical studies of perception. ${ }^{[13]}$ In this sense, pitch segments are not different from alphabetic letters: they do not, in and of themselves, project meaning. They both demand contexts within which meaning can take shape. Let us use language to make this point clear, using a single sentence as a basis for clarity:

"Maureen regretted very early that her daughter had inherited her Father's exaggerated style of laughter."

These fifteen words unite; they make a readily decipherable message, a meaningful context. Do they project additional meanings one must apprehend to fully understand their message? Are there structural cues beyond verbs, subjects, clauses, et al., that one must uncover in order to fully comprehend their full meaning? Only if one seeks hidden codes where others fear to tread, like John Nash of $A$ Beautiful Mind. And even then, breaking a code may not yield a real addition to the message!

Going back to our model sentence, let us study the mini-details of those fifteen words. Careful analysis can reveal some repeated adjacencies, in this case forming an inherent property of dominance. The letter succession $\mathrm{er}$ and its retrograde $r e$ occurs more often than any other (eleven times); it is the most prominent letter coupling of the sentence-if one is interested in letter-couplings.

There is but one plausible response to this discovery of imbedded dominance: "So What?"

This insider datum - readily confirmed by count — has nothing to do with the sentence's message. Those eleven er/re bits don't rise to the threshold of structure, where linguistic meaning resides. Unless consciously sought, they are not even noticed, whether read or spoken ${ }^{[14]}$ And so it is with the intervallic bits of "local continuity" and "cross association" Professor Babbitt isolates in those opening Schoenbergian 
"sentences." As models for "determinate and testable statements about musical compositions" they fall short of compelling. This focus on the "ordered adjacencies" of row segments per se, as carriers of "local continuity and association," represents armchair theorizing; they are not descriptions of music. A more accurate picture unfolds in psychologist Diana Deutsch's empirical confirmation of a well-known Gestalt principle: "We work with different hierarchical levels, together with their rules of combination" (Deutsch, 1980, p. 381). Or even more pertinent to Babbitt's analysis of Schoenberg, as Michael Martinez has noted: "The human mind is not a video camera. We do not store and process countless sensory bits; rather, we construct our inner and outer worlds according to the organizing principle of meaning" (Martinez, 1999, p. 18).

Analyses such as those of Babbitt are stark reminders of musician Don Gibson's (1993) broad conclusion drawn from extensive studies. It is that the assumptions and relationships typical of the analyses of serial music are best treated with skepticism. They depend too heavily upon written notes rather than heard tones. Notation provides a kind of musical recipe: the taste of the final dish is something else.

I wonder: Is audition even pertinent to such descriptive "analyses" and "explanations" made within the realm of Serialism? It's easy to interpolate "meanings" from written notes. Like claims of Pythagoras and gurus of the Joseph Schillinger ilk, ${ }^{[15]}$ serialist claims are stated with a resolute precision that shades their feeble implications for perception.

Such discussions as Babbitt's are not rare in the hardcore literature of music from over the past five decades. They bear a scholasticism that could endure only in academe, just as the more arcane products of scholasticism in ancient times could survive only in monasteries. The ultimate misfortune is that musicology is replaced by cryptology. That conclusion is not mine alone. Thomas Regelski touched upon the overarching problem more than a decade ago. He attributed its causes to a loss of perspective, an indifference to musical realities. As he put it,

In seeking the "exact observation and strict correlation of data" more suitable to the inanimate subject matter of the physical sciences, many music researchers have disintegrated the subject matter of music - its musical integrity, its human interest - to the degree that their results are irrelevant and of no theoretical interest or pragmatic use (1996, p. 12).

\section{EMPIRICAL BASES FOR VITAL WORDS}

Even the vocabulary of the serialist world is both cramped and stretched to fit fancied conditions, conditions that reinforce an aura of systemic certainty. Take the term atonal: it's a vital word of the music vocabulary, but it has been so bandied about that its necessary root word tonal becomes indefinable. Schoenberg fancifully side-stepped it, as applied to his own music, noting that since his music contained tones, it could not be described as "atonal." It has been freely applied by authors from Allen Forte (1973) and George Perle (1968) to Ethan Haimo's (2006) "revisionist thesis." ${ }^{\text {"[6] }}$ Whatever its meaning, the term has been used most often when the musical substance seemed to lack the kinds of pitch orientation prescribed for music limited to the Classical and Romantic eras. But should we not share a more basic meaning for the term? Should we not know what aural experience, what musical condition prevails when the word applies to the repertoire of any era, when something can be confirmed perceptually as atonal? Do we have precise and encompassing ways for answering questions about what conditions prevail when atonality is present?

A volume entitled The Structure of Atonal Music could be expected to harbor a commune of tight definitions, at least one of which — if not all-might illuminate the issue. But this early classic of the serialist genre is shockingly devoid of orientation. ${ }^{[17]}$ One must decide independently what the absence of a tonal condition - thus atonal-might be. And that's not easy when author Allen Forte claims that Stravinsky's Rite of Spring is atonal. I'll spare my reader a review of that historic music, with its plethora of indelible tonic pitches (beginning with the bassoon's opening filigree around $A$ ). A full disclosure of the flaw in Forte's definitive conclusion would demand such.

Even more damaging than lexical sloppiness is the absence in Forte's book of a defining discussion of the atonal condition discussed in its subsequent 220 pages. We are left to conclude, with Schoenberg's assenting nod, that any music unfounded in the I, IV, and V chords of major or minor scales, like those found in church hymnals, is atonal.

A nimble skirting of the issue occurs when Forte notes in his book's Preface (ix) that "Many gifted composers contributed to the [atonal] repertory: Alexander Scriabin, Charles Ives, Carl Ruggles, Ferruccino Busoni, and Karol Szymonowski." And then we get down to bare facts: "Any composition that 
exhibits the structural characteristics that are discussed [in this book], and that exhibits them throughout, may be regarded as atonal."

Forte's guidance recalls an old intellectual saw prized from childhood by Bertand Russell:

"What is mind?"

"No matter!"

And what is matter?"

"Never mind!"

This absence of empirical basis has flourished over the past several decades, especially in struggles by scholars to elucidate music rich in chromaticism. An extensive study by musician Nathan Haimo begins with a discussion of the "tis" and "taints" of atonal. His best conclusion is that the term's meaning is "dubious" (2006, p. 3).

The pre-12-tone, or "atonal," music of Schoenberg has provided a veritable workshop for contradictory demonstrations of meaning that seem to confirm that dubious state. His Opus 11 of 1909 is a classic of the genre. Reading accounts of the "true" nature of that work's pitch structure can be an education in the vagaries of academic scholarship. A single issue of the journal published by the original Arnold Schoenberg Institute is a primer for the course. It begins with an extended article by Forte, who posits the reigning canon that Opus 11, No. 1 is unquestionably atonal. In his judgment it furthermore is "the first work without text that depends solely upon its atonal musical organization for its coherence and beauty" (Forte, 1981, p. 127). Forte's conclusion has been shared by many imposing scholars, Rudolph Reti (1962), Jan Maergaard (1972), George Perle (1968), Bryan Simms (2000), and Gary Wittlich (1974), to mention only those who have made the strong arguments.

As irony would have it, however, there have been as many who "hear a different song" in $O p$. 11 , No. 1 (see Figure 7). Among those non-believers have been Hugo Leichtentritt, who affirmed evidence of a "Phrygian tonality" rooted in $E$; Reinhold Brinkman (2000) finds a pitch "domain" of the $5^{\text {th }} B-E$ essential to the work's pitch structure; Edwin von der Nüll (1932) claims an $E$ major-minor caste for the piece); and Jim Samson (1993) refers to the movement's "residual tonality," with E-flat playing a "centralizing function in the piece as a whole." And then the most forceful-if specious - argument of all is made by Wilbur Ogden (1981) who finds even a tonal Exposition-Development-Recapitulation for the work, all dominated by a tonic $G$ established within the movement's first six measures.

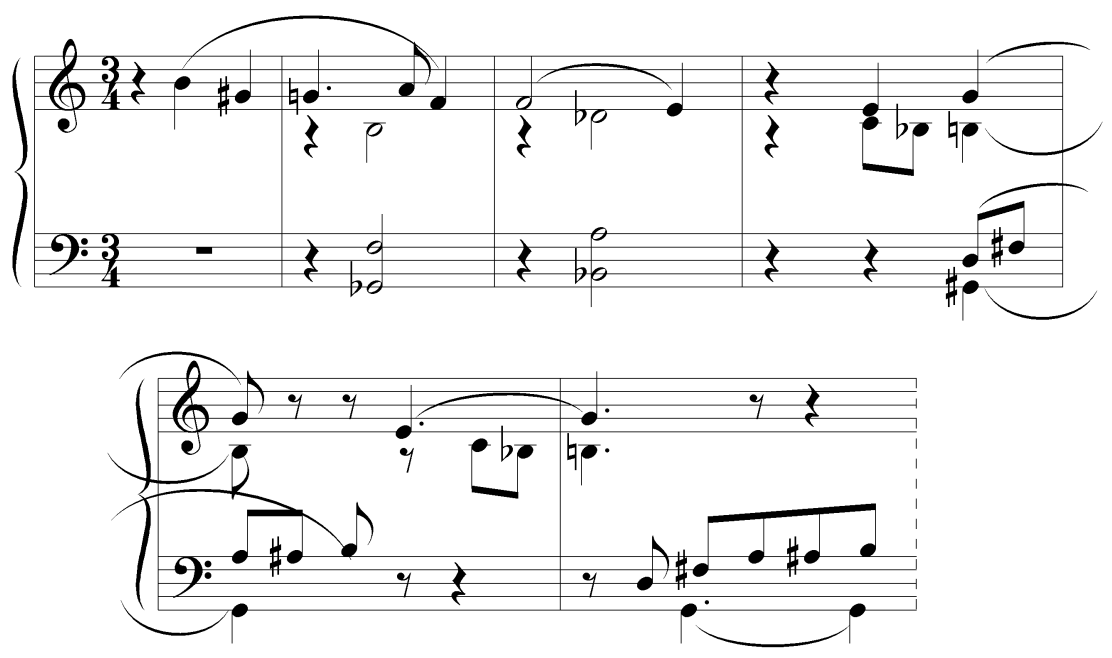

Figure 7. Opening, Schoenberg's Opus 11, No. 1 (1909).

So we are led to ask: "How could such a brief work elicit such contradictory explanations of such an elemental property?" Is it possible they are all right? Or is it not more likely that at least $50 \%$ of these conclusions are based on a flawed conception of what tonality (and thus of its absence) might be? After all, Schoenberg was convinced that his little piece was "relatively easy to understand." [18] And yet, if these contradictory interpretations flourish, lexical flaws - if not perceptual inadequacies — must flourish as well. 
The literature suggests that no empirical basis is known for what is experienced as "atonal." And this is not true.

\section{"TONICS WITHOUT TONALITIES"}

There are further deep mysteries embedded in serialist lore revolving around rambunctious uses of the words tonal and atonal. Many are a result of the wish to find traditional conditions within compositions clearly hewn from serialist note processings. ${ }^{[19]}$ Music theorist David Lewin devoted many years attempting to reveal that some of the serial and atonal repertoire is blessed with New-Age versions of tonality. His vocabulary is impressive. He found "pitch-centered presences," "pitch-class axes," "antipodal centers," "harmonic bondings of pitch-classes," "antipodal axes," "pitch centers," and "centers of inversion" in that never-never world of abstraction, pitch-classes. All claim tonalities-in-hiding.

Lewin's prose can achieve misty heights comparable to Babbitt's. His words are most often a product of his will to explain simple matters with the precision of space mission plans. A representative example of his lexical care quoted below involves a description of what are called "complementary sets." It reads as follows:

"If $\mathrm{P}$ is a collection of notes, the complement of $\mathrm{P}$ is defined to be the collection of all notes not in $P$. Thus, in the sense in which I use the word "note," if P contains X notes, the complement of P contains 12 - X notes, and has no notes in common with P. I shall write $\mathrm{P}^{\prime}$ to denote the complement of P" (1960, p99).

Or, translated for the unsaved: "I call a collection of notes $P$. All notes not in that collection I call $P$ '."

Several of Lewin's discoveries rank with $19^{\text {th }}$ century thinkers' "proof" of origins for the minor triad in the Undertone Series. ${ }^{[20]}$ He finds pitch-classes participating in hierarchical clottings that, he suggests, are meaningful as heard music. ${ }^{[21]}$ He finds them in \#14 of Schoenberg's Pierot Lunaire as well as in the opening scene of Moses und Aron. In the latter he vouches for the "strong tonic character" of the chord $A-B$-flat- $E$ (Lewin, 1968, p100). The sonority itself is an exotic choice for such a role, although the Bebop of Dizzy Gillespie and Charlie Parker often ended with even more complex "tonic" chords, yet chords clearly related to an established pitch hierarchy-a "key.".

We are assured that similar echoes of tonal things occur in Schoenberg's later serial music as well. They are reminiscent, we are told, of the "balances" induced by tonal centers of old. This motivation to uncover deep structural correspondences with past times leads Lewin to erode the very meaning of the word tonic; his use wins as one of the century's catachrestic classics. Like Forte's atonal, it's a condition hard to pin down experientially. But whatever it means, we are aware of its presence, according to Lewin, in Schoenberg's String Quartet No. 3.

The name he uses for that condition is worthy of Derrida: tonic abstract texturing. Or as it is less colorfully expressed in other contexts, the work's row and its inversion offer "dual centers." These dual $p-c$ centers are said to empower the passage with "contextual pitch axes."

The origins for this dual centricity are found in the Quartet's row $(O)$ and its transposed inversion (It5) (see Figure 8).

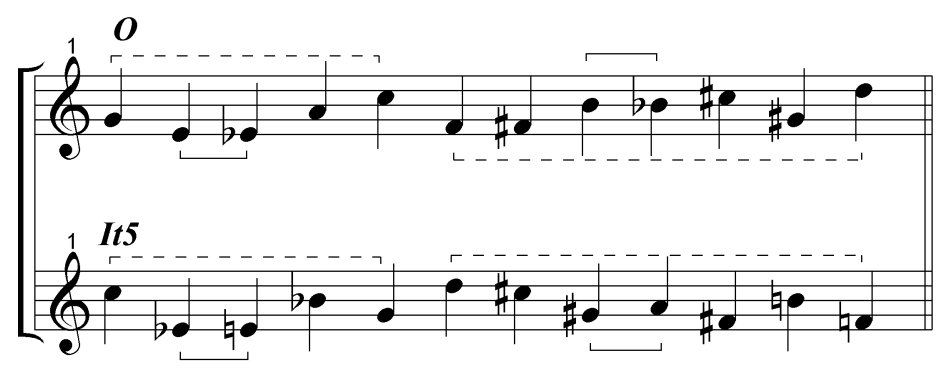

Figure 8. Quartet's Pitch set and its inversion (It5).

Having promised "tonics," Lewin embellishes on this structural embodiment when he reminds us (p. 12) that "'tonic sense' in this piece is attributed not simply to the basic set, but to the set, plus a basic 
pitch class inversion I, plus the abstract texturing that results when $\mathrm{S}$ is compared to $\mathrm{I}=\mathrm{I}(\mathrm{S})$.” Evidence for Lewin's claim can most readily be seen in Mvt. III, mm. 64-68, and in the final measures of the Quartet's last movement. But as perceived music it all amounts to a latter day riff on Schoenberg's touted claim for the Grundgestalt, the condition of any row projecting a perceptual unity to its musical product. ${ }^{[23]}$

Even if true, we still must ask: "So what is tonic - if there be such?" And what pitch conditions tie this passage to the same kind of aural presence we hear in a phrase by Haydn or Hindemith? Lewin suggests that it "is embodied in"- the $p-c$ duality $E$ - $E \mathrm{~b}$ within the row's initial grouping of five. It has been called one of the "centers" for this Set/It5 match; the other is the $A \#-B$ conjunction in the 7-note grouping.

So what are we to believe? Are there "dual centers" in these contexts, one whose focus is on $E$ $E \mathrm{~b}$, the other on $B-A \#$ ? Or is it a matter of just $E \mathrm{~b}$ and $E$ or $A \#$ and $B$, plus $A$ and $G$-sharp? And if any of this be true, is the Emperor not overdressed? But let us face once again a simple fact: the condition of noteprominence is not of the same realm as tonicality or tonality or tonic or pitch centricity.

Like the $E-E b$ duplication, the $5 \times 7$ row compartmenting can be found in the notes. But there is no evidence that what we hear from those notes projects any kind of oxymoronic tonicality: two pitchclasses as pitch Axes? Could this be music's counterpart to cross-eyed vision? Are these fleeting "wiggles," as Lewin calls them, sufficient to launch a "tonic"? Or even, as claimed, a "sense of tonic?" And just how does a "sense of tonic" differ from a "perception of tonic?" Equating this condition discovered in dodecaphonic notes with contexts of tonics evident in tonal music is far-fetched at best, irresponsible at worst. ${ }^{[24]}$ The idea consolidates further the concept of Grundgestalt, but in this case the row is segmented into groups of 5 and 7 notes, each group bearing its own "tonic-sense."

Lewin's attempts to link dodecaphonic note conditions to structural imperatives of bygone days is admirable. If his ties were valid they could represent a welcome bond between past and present, a healthy trend toward theoretical reductionism. Theorist Richard Kurth has suggested that these random moments of tonic sense, these Scheintonalitäts momente, are but accidents of serialist methods. In a sentence worthy of Babbitt or Lewin he claims that they "result from temporary imbalances in the twelve-tone system's abstract counterbalancing of multiple tonal relationships" (Kurth, 2001, pp243-244.)

He may be right.

But there are good reasons to believe that searches for fleeting "tonics" lead only to unsubstantiated sightings of sonic phantoms. Lewin's Search-and-Discovery approach is wholly consistent with the Deconstructionism popularized late in the past century and still engrained in some academic psyches today. Like Freudian psychology, it is an approach to knowing that separates words from their surface definitions, then seeks more profound meanings by analyzing surrounding text for other, deeper messages. Most disturbing is the trend to behave as though the actual musical artifact is less important than the technical canon of its creation. As Allen Shawn has observed, too much writing about music today

"implies that the very purpose of the "foreground music," the purpose of what you hear, is actually to express the "background"- that what you hear is about the underlying structure, not the other way around" (2002, p. 296).

In a slightly different way from Lewin, composer-theorist George Perle argued a slightly different brand of serialized tonal resonances, one of "pitch centricities," "tonics," and "tone centers." ${ }^{25]}$ He excuses the troubled marriage of Pitch Center with Atonal Music by slipping out a lexical side door hung in 1963 by Arthur Berger ${ }^{[26]}$ who adopted the designation "pitch-class priority."[27]

Like Lewin's resurrections of abstract notes as "pitch-class axes," Perle's are forced, perceptually beside the point. They are close kin with Babbitt's description of pitch prominences. Whatever the pitch kinetics of a given locale, listeners would have to attend methodically to certain pitches as they flit by, then note their recurrences (or their pitch-class resurrections) to fit them into hierarchies. It would demand a frenetic context-on-the-go process, far beyond normal audition. Such picayune notions only further erode our understanding of words like tonic and tonal center, both of which are contextually defined. Criteria for what are structural pitches and what are not (aside from their tonal meanings) most often turn upon local rhythmic emphasis, textural deployments, timbral prominences, or loudness levels. None of those are pitch causes. We must wonder if the word prominence, rather than centricity or priority might better fit the described conditions.

And there is at least one further consideration of import. As suggested earlier, statistical prominence in traditional tonal music doesn't always produce contextual dominance. Even the statistically evident reciting tones of Gregorian chant were differentiated as structurally secondary to the modus finalis. The tonic of many a folk and pop tune is among the least heard pitches: they just show up in the most prominent places. In a study of English folksongs, ${ }^{[28]}$ Hans Reichenbach (1938) discusses pitch dominance for eighteen tunes in the Dorian mode. The note $D$ (Final) is exceeded in duration by the note $A$ 
(Dominant), 271 vs. 234.5. For this reason, those who only count notes to find structural dominances must be reminded of Arthur Koestler's classic indictment: purely statistical data are like the Bikini bathing suit. "What they reveal is provocative, but what they conceal is crucial."

I suggest that Perle and Lewin leave skeptics with nothing better than a latter day conundrum: "What is a tonic without tonality the tonic of?" Or for the grammatically sensitive: "If there can be such a form of pitch centricity, what species of sensate elements is centered?" Is it a pitch or a pitch-class?

Such realizations lead us to the oft-repeated hunch that music as sonic being is not the controlling goal for many of the most cherished accountings of Serialism. The artificial respiration that has kept that doctrine intact and upstage in the academic world is not fundamentally different from that which continues to dissect and ennoble the opaque literary gems of Gertrude Stein and Ezra Pound. Tom Wolfe's insight was monumental when he observed that the Art of it all "has become completely literary: the composition exists only to illustrate the text" $(1975$, p. 3).

In Serialism the text gains the spotlight. Its words imply descriptions of real music, allowing, nonetheless, that such music is so complex that its understanding requires special indoctrination into the procedures that fostered its creation. A classic description of the genre is a single sentence in a discussion by Babbitt of Schoenberg's Concerto for Violin and Orchestra. It personifies the implicit—and often ignored - concern for pre-compositional note juggling rather than audible result. As he notes,

"The rhythmic character of this presentation most strikingly articulates - by a rest - the set into two halves, two distinct hexachords, and immediately suggests the fundamental role of hexachords in the set, and so in the work ..." (2003, p. 224).

A more rational perspective was philosopher Andrew Ushenko's take on "structural" explanations of art objects. Describing any medium, he argued that "to perceive the aesthetic effect we do not need to know the rules for its execution. Artistic truth is in art, not about art" (1953, p. 183). Or as painter Charles Demuth once put it, "no writing, no singing, no dancing will explain them."

In closing, let me posit a simple conclusion implied earlier: classic tracts of the serialist world impose one knowledge domain upon another, one to which they are ill-suited. The most precise and thorough itemizations of how notes were assembled cannot reflect contextual kinematics, how "moving" parts develop meaning in time. For this reason many serialist "explanations" are but bayings at a fictive moon, regardless of the precision of their discoveries. Theorist Richmond Browne enunciated a similar conclusion in the summation (p. 401) of his review of Allen Forte's The Structure of Atonal Music:

I conclude that the goal I, they, we seek is the phenomenological experience of pitch orientation we learned under tonality to call music, and I conclude that it is an exaggerated quest to try to find, beneath the surface of non-tonal music, a potential source of pitch coherence which, if we could only work hard enough, would give us "tonal security." The essence of natural language and gestalt is that you don't have to (can't, in fact) look for it. It presents itself.

But— just to keep all conceptual doors open-let us bend over backwards to avoid forgetting an alternative perspective. Those of us who do not find relevant all aspects of the dodecaphonic cant may only suffer as musical troglodytes. Many of us lack absolute pitch recall, and we may also be incapable of the advanced hearing demanded by passages freighted with meanings exhumed from elaborate noteprefabrications - keeping in mind, of course, that serialist doctrine may, on the other hand, be nothing more than lingering remnants from a failed Arts Revolution of the past century.

\section{NOTES}

${ }^{1}$ The content of this paper is drawn from Chapter 7 of the author's book MetaMusic Versus the Sound of Music, published by Edwin Mellen Press, 2010.

${ }^{2}$ A pitch-class $(p-c)$ is any member of the twelve notes of the chromatic scale in any of its audible registers. Thus p-c refers to all A-flats (and G-sharps), et al., within music's notational system.

${ }^{3}$ Among the most prominent have been those of C.L. Bruner, Niccola Dibben, , Diana Deutsch, W.J. Dowling, Don Gibson, and Carol Krumhansl. 
${ }^{4}$ Benjamin Boretz, quoted in the book jacket "advance praise" of The Collected Essays of Milton Babbitt.

${ }^{5}$ His public disclosure of what he regarded as the dead ends of Serialism appeared in 1973, in "Reflections on Schoenberg."

${ }^{6}$ I think this phrase should end with the closing of parentheses, but the original copy does not.

${ }^{7}$ The term interval-class refers to the generic relation, regardless of octave separation, of any two pitchclasses. There are only six "interval-classes, beginning with 1 (semitone) and ending with 6 (tritone). The total lineup of interval-class successions in Schoenberg's row is: $I C 1=5 ; 2=1 ; 3=0 ; 4=3 ; 5=2 ; 6=0$.

${ }^{8}$ An intent listener might more readily recall the Quartet's first movement, with its opening semitone of motivic prominence.

${ }^{9}$ Or, more correctly, five $I C 1 \mathrm{~s}$.

${ }^{10}$ Related discussions can be found in Handel, S. (1989); Schmuckler, M.A. (2009); Thompson, W.F. (2009) Chapter 5.

${ }^{11}$ For a discussion of pertinent matters see Bregman, A.S. (1990).

${ }^{12}$ The second segment would have to contain $G$-sharp rather than $B$ to form an inversion of the first segment.

${ }^{13}$ Including those of Bruner; Dibben; Dowling; Francés; Dienes \& Loguet-Higgins; and Krumhansl, Sandell, \& Sargeant, to cite only a few.

${ }^{14}$ And by all means note that the retrograde condition borne by $r e$ to $e r$ is wholly irrelevant.

${ }^{15}$ The Schillinger System of Musical Composition (1946) was a hot mid-20 $0^{\text {th }}$ century by-the-numbers approach to composition. Gershwin studied it and band leader-arranger Glen Miller was alleged to have composed his dance band's theme song, Moonlight Serenade, using it.

${ }^{16}$ Especially note Forte's title for an article of 1981: “A Musical Kaleidoscope: Schoenberg's First Atonal Masterwork, Opus 11. No. 1."

${ }^{17}$ In George Perle's opinion ("Pitch-Class Analysis: An evaluation") the book suffered "ways of talking about and analyzing music that have nothing whatever to do with what I would call 'common sense' experience."

${ }^{18}$ Style and Idea, 79.

${ }^{19}$ Schoenberg himself spoke of future audiences who would recognize the tonality within music then known as atonal. (Style and Idea, 284)

${ }^{20}$ One of those hilarious "discoveries" of music history, the "Undertone Series" was a construct based on the ordering of the very real Overtone Series, but in the opposite direction.

${ }^{21}$ Lewin allows that "we may think of these p-c inversions as possessing axes; each also may be regarded as having a pair of "antipodal centers." The reader is left to wonder how things that exist only as imagined classes of things (like pitch-classes) can possess such real-world spatial properties.

${ }^{22}$ I have chosen my words carefully with the hope of not altering Lewin's claim. 
${ }^{23}$ Schoenberg's most direct claim for the row's Grundgestalt role appears in "My evolution," Style and Idea., 91. This context-provoking power of a row, as a collection of pitch-classes, has been repeated often by those arguing the powers of serialist procedures.

${ }^{24}$ For a discussion of suchj matters see Thomson, "From sounds to music: the contextualizations of pitch."

${ }^{25}$ Perle studied composition with one of the elders of the 12-tone canon, Ernst Krenek.

${ }^{26}$ In "Problems of Pitch Organization in Stravinsky."

${ }^{27}$ The coinage may have influenced David Lewin's judgment too.

28 "English and Gaelic Folksong," 271. He shows tallies for tunes in other modes too.

\section{REFERENCES}

Babbitt, M. (2003). The Collected Essays of Milton Babbitt (Stephen Peles, Ed.). Princeton: Princeton University. Press.

Berger, A. (1963). Problems of pitch organization in Stravinsky. Perspectives of New Music, 2(1), 11-42.

Bregman, A. S. (1990). Auditory Scene Analysis: The Perceptual Organization of Sound. Cambridge, MA: MIT Press.

Boretz, Benjamin (2003). Book jacket note, The Collected Essays of Milton Babbitt.

Brinkmann, R. (2000). Arnold Schönberg: Drei Klavierstuecke Op. 11: Studien zur fruehen Atonalitaet bei Schoenberg. Stuttgart: F. Steiner.

Browne, Richmond (1974). "Forte's The Structure of Atonal Music (Review)." Journal of Music Theory 19, 390-409.

Bruner, C. L. (1984). The perception of contemporary pitch structures. Music Perception, 2(1), 25-39.

Deutsch, D. (1980). The processing of structured and unstructured tonal sequences. Perception and Psychophysics, 28, 381-389.

Dibben, N. (1994). The cognitive reality of hierarchic structure in tonal and atonal music. Music Perception, 12(1), 1-25.

Dienes Z. \& Longuet-Higgins, C. (2004). Can musical transformations be implicitly learned? Cognititive Science, 28(4), 531-558.

Forte, A. (1973). The Structure of Atonal Music. New Haven: Yale University, Press.

Forte, A. (1981). The magical kaleidoscope: Schoenberg's first atonal masterwork, Opus 11, No. 1. Journal of the Arnold Schoenberg Institute, 5(2), 127-168.

Gibson, D. (1993). The effect of pitch and pitch-class content on the aural perception of dissimilarity in complementary hexachords. Psychomusicology, 12(1), 58-72.

Haimo, E. (2006). Schoenberg's Transformation of Musical Language. Cambridge: Cambridge University Press. 
Handel, S. (1989). Listening: An Introduction to the Perception of Auditory Events. Cambridge, MA: MIT Press.

Krumhansl, C. L., Sandell, G. J. and Sargeant, D. C. (1987). The perception of tone hierarchies and mirror forms in twelve-tone serial music. Music Perception, 5(1), 31-78.

Kurth, R. (2001). Suspended tonalities in Schönberg's twelve-tone compositions. Journal of the Arnold Schönberg Center, 3, 239-265.

Lewin, D. (1960). Re: The intervallic content of a collection of notes, intervallic relations between a collection of notes and its complement: An application to Schoenberg's hexachordal pieces. Journal of Music Theory, 4(1), 98-101.

Lewin, D. (1968). Inversional balance as an organizing force in Schoenberg's music and thought. Perspectives of New Music, 6(2), 1-21.

Maegaard, J. (1972). Studien zur Entwicklung des dodekaphonen Satzes bei Arnold Schönberg. Copenhagen: W. Hensen.

Martinez, M. E. (1999). Cognitive representations: distinctions, implications, and elaborations. In: I.E. Sigel (Ed.), Development of Mental Representation. New Jersey: Lawrence Erlbaum Associates.

Ogden, W. (1981). How tonality functions in Schoenberg's Opus 11, No. 1. Journal of the Arnold Schoenberg Institute, V(2), 169-181.

Perle, G. (1968). Serial Composition and Atonality : an introduction to the music of Schoenberg, Berg, and Webern. $2^{\text {nd }}$ edition. Berkeley and Los Angeles: University of California Press.

Regelski, T. A. (1996). Scientism in experimental music research. Philosophy of Music Education Review, 4(1), 3-19.

Reichenbach, H. (1938). The tonality of English and Gaelic folksong. Music and Letters, 19(3), 268-279.

Reti, R. (1962). Tonality in Modern Music. $1^{\text {st }}$ Collier Books edition. New York: Collier Books.

Rochberg, G. (1973). Reflections on Schoenberg. Perspectives of New Music, 11(2), 56-83.

Samson, J. (1993). Music in Transition: A Study of Tonal Expansion and Atonality, 1900-1920. Oxford, UK: Oxford University Press.

Schmuckler, M.A (2009). Components of melodic processing. In: S. Hallam, I. Cross, and M. Thaut (Eds.), Oxford Handbook of Music Psychology. Oxford, UK: Oxford University Press, 93-106.

Schoenberg, Arnold (1975). Style and Idea (Ed. Leonard Stein). New York: Faber and Faber.

Shawn, A. (2002). Arnold Schoenberg's Journey. New York: Farrar, Strauss and Giroux.

Simms, Bryan (2000). The Atonal Music of Arnold Schoenberg 1908 -1923. New York: Oxford University Press.

Thompson, W.F. (2009). Music, Thought, and Feeling: Understanding the Psychology of Music. New York: Oxford University Press.

Thomson, W. (1991). Schoenberg's Error. Philadelphia: University of Pennsylvania Press.

Thomson, W. (1993-94). Music as organic evolution: Schoenberg's mythic springboard into the future. College Music Symposium, 33/34, 191-211. 
Thomson, W. (1999). Tonality in Music: A General Theory. San Marino, California: Everett Books.

Thomson, W. (2004). From sounds to music: the contextualizations of pitch. Music Perception, 21(3), 431456.

Ushenko, A. (1953). The Dynamics of Art. Bloomington: Indiana University Press.

Von der Nüll, E. (1932). Moderne Harmonik. Leipzig: F. Kistner \& C.F.W. Siegel.

Wittlich, G. (1974). Interval and set structure in Schoenberg's Op. 11, No. 1. Perspectives of New Music, 13(1), 41-55.

Wolfe, T. (1975). The Painted Word. New York: Farrar, Strauss and Giroux. 